Revista da Universidade Estadual de Alagoas/UNEAL

e-ISSN 2318-454X, Ano 12, Vol. 12(2), 2020

\title{
Dificuldades na elaboração e execução de projetos de educação ambiental em escolas públicas
}

\section{Difficulties in the elaboration and execution of environmental education projects in public schools}

\author{
Cristiano Cunha Costa! \\ Universidade Federal de Viçosa
}

E-mail do autor principal: cristianocunha1982@hotmail.com

\begin{abstract}
Resumo - O presente trabalho se apresenta como um relato de experiências vividas durante a elaboração e execução de projetos de educação ambiental de forma participativa por professores e alunos em escolas públicas da cidade de Aracaju e do interior do estado de Sergipe. O objetivo foi relatar sobre as dificuldades enfrentadas durante a elaboração e execução dos projetos de educação ambiental em escolas públicas, que muitas vezes culminam no não atendimentos dos objetivos propostos. Observa-se que há pouco interesse de alguns professores no envolvimento dos projetos, falta conhecimento prático e teórico sobre educação ambiental, gerando uma confusão sobre termos como multi e pluridisciplinar, inter e transdisciplinar e resultando em ações ambientais restritas a datas comemorativas. Além disso, o Projeto Político Pedagógico de algumas escolas não contempla as ações de educação ambiental. Tais projetos de educação ambiental exigem uma nova configuração no meio escolar com objetivos e metodologias interdisciplinares, envolvendo a qualificação do professor e inclusão do saber ambiental a nova proposta político-pedagógica.
\end{abstract}

Palavras-chave: Metodologias interdisciplinares. Participação. Proposta político-pedagógica.

Abstract - The degradation of the environment has been highlighted due to the increase of
human activities, causing huge losses to natural resources and biodiversity, resulting in the
decrease of the population's quality of life. Thus, schools have been interesting areas as
regards the formation of full citizens, emphasizing, among its functions, instigate reflection on
the subject and its identity and view of the world and, for example, on environmental issues.
Such work is pesented as an account of experiences during the development and
implementation of environmental education projects in a participatory manner by teachers and
students in public schools in the city of Aracaju and the State of Sergipe. The goal is to report
on the difficulties faced during the development and implementation of environmental
education projects at public schools, which often not culminate in the proposed objectives. It
is observed that there is little of interest of teachers in the involvement of projects, lack
practical and theoretical knowledge on environmental education, creating confusion about
terms like multi and multi-disciplinary, inter- and transdisciplinary and resulting in
environmental actions restricted to holidays. In addition, the Pedagogical Political Project of 


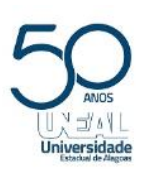

Revista Ambientale

Revista da Universidade Estadual de Alagoas/UNEAL

e-ISSN 2318-454X, Ano 12, Vol. 12(2), 2020

some schools does not address the environmental education. Such environmental education projects require a new configuration at school with goals and interdisciplinary methodologies, involving the teacher's qualification and inclusion of environmental knowledge the new educational policy proposal.

Keywords: Interdisciplinary methodologies. Participation. Political-pedagogical proposal.

\section{Introdução}

A degradação do meio ambiente tem se destacado por conta do aumento da ação antrópica, causando enormes prejuízos aos recursos naturais e à biodiversidade, tendo como consequência o decréscimo da qualidade de vida da população. Dessa forma, as escolas, através de projetos de educação ambiental, têm sido espaços interessantes no que se refere a formação de cidadãos plenos, destacando-se, dentre suas funções, instigar a reflexão no sujeito quanto a sua identidade e postura diante do mundo e, por exemplo, diante das questões ambientais (COSTA, 2019).

Diante desse contexto, é possível trabalhar o meio ambiente de forma interdisciplinar, fazendo ligação entre todas as disciplinas e abandonando a ideia de que os conhecimentos das disciplinas são fragmentados. $O$ atual sistema de currículo não permite que a educação ambiental seja uma disciplina, devido a sua complexidade de fatores que interagem entre si. Assim, torna-se necessário que a educação ambiental seja trabalhada de forma interdisciplinar onde as questões ambientais permeiem todas as disciplinas (SILVA et al., 2015).

É dentro desse contexto que se insere a importância da elaboração e desenvolvimento de projetos de educação ambiental, pois se pretende envolver alunos e professores na discussão da relação antrópica com o meio ambiente com o fito de promover a sensibilização, favorecendo a mudança de hábitos, comportamentos e atitudes (MODESTO; ARAÚJO, 2014).

Por outro lado, tais projetos enfrentam diversos obstáculos que vão desde a desvalorização profissional, falta de conhecimento de conceitos teóricos e práticos sobre educação ambiental, desinteresse dos demais professores, dentre outros. Desse modo, tais fatores que interferem, isoladamente ou cumulativamente, contribuem para o insucesso dos projetos ambientais (BARBOSA et al., 2015).

Tal trabalho se caracteriza por ser de cunho teórico-empírico através de um relato de experiências vividas durante a elaboração e execução de projetos de educação ambiental formal, servindo de informações e discussões norteadoras para eventuais dificuldades que possam ser empecilhos para a execução das ações de educação ambiental.

O objetivo foi relatar sobre as dificuldades enfrentadas durante a elaboração e execução dos projetos de educação ambiental em escolas públicas no ensino fundamental da cidade de Aracaju e do interior do estado de Sergipe, recorrendo, também, a literatura especializada para poder embasar teoricamente as observações que constam no trabalho e analisar as perspectivas e valores que os projetos de educação ambiental pode proporcionar ao indivíduo no ensino formal. 


\section{Referencial teórico}

\section{Evolução conceitual da educação ambiental}

A Internacional Union for the Conservation of Nature (IUCN), na década de 70, definiu a educação ambiental como um processo de reconhecimento de valores e clarificação de conceitos, voltado para o desenvolvimento de habilidades e atitudes necessárias à compreensão e a apreciação das interpelações entre o homem, sua cultura e seu entorno biofísico (DIAS, 2010).

Na Conferência de Tbilisi (1977), foi definida como uma dimensão dada ao seu conteúdo e prática da educação, orientada para a resolução dos problemas concretos do meio ambiente, através de um enfoque interdisciplinar e de uma participação ativa e responsável de cada indivíduo e da coletividade. Essa educação deveria preparar o indivíduo, mediante a compreensão dos principais problemas do mundo contemporâneo, proporcionando-lhe conhecimentos técnicos e qualidades necessárias para desempenhar uma função produtiva, com vistas a melhorar a vida e proteger o meio ambiente, prestando a devida atenção aos valores éticos (DIAS, 2010).

Para Barros e Silva (2019), é necessário que o ser humano entenda que ele far parte rda natureza e, como tal, detentor de conhecimentos e valores socialmente produzidos age, permanentemente, sobre sua base natural de sustentação, alterando suas propriedades e, em decorrência deste processo interativo, a sociedade, também, sofre modificações em sua dinâmica.

A Organização das Nações Unidas para Educação, Ciência e Cultura (UNESCO), em 1987, definiu a educação ambiental como sendo um processo permanente no qual os indivíduos e a comunidade tomam consciência do seu meio ambiente e adquirem conhecimentos, habilidades, experiências, valores e a determinação que os tornam capazes de agir, individual ou coletivamente, na busca de soluções para os problemas ambientais, presentes e futuros (MMA, 2016).

No Congresso Internacional sobre Educação e Formação Ambiental, realizada em Moscou (1987), concordou-se que a educação ambiental deveria, simultaneamente, preocupar-se com a promoção da conscientização, transmissão de informações, desenvolvimento de hábitos e habilidades, promoção de valores, estabelecimento de critérios e padrões, e orientações para a resolução de problemas e tomada de decisões. Portanto, deveria objetivar modificações comportamentais nos campos cognitivos e afetivos (MMA, 2016).

A educação ambiental promove a sensibilização a qual ocorre entre o "eu" e o "outro", pela prática social reflexiva e fundamentada teoricamente. A ação conscientizadora é mútua, envolve capacidade crítica, diálogo, a assimilação de diferentes saberes e a transformação ativa da realidade e das condições de vida através de um processo compartilhado com ações conjuntas e participativas (SOUZA; MARCO, 2020). Desse modo, esse processo de conscientização pode ocorrer a partir da educação ambiental formal ou informal. 
Revista da Universidade Estadual de Alagoas/UNEAL

e-ISSN 2318-454X, Ano 12, Vol. 12(2), 2020

\section{Modalidades da educação ambiental}

Pela Política Nacional de Educação Ambiental, a educação ambiental, como um "componente essencial e permanente da educação nacional, deve estar presente em todos os níveis e modalidades do processo educativo, em caráter formal e não formal" (BRASIL, p. 4, 1999). Dessa maneira, diante da sua versatilidade a educação ambiental pode ser dividida em: educação ambiental formal e não formal (figura 1).

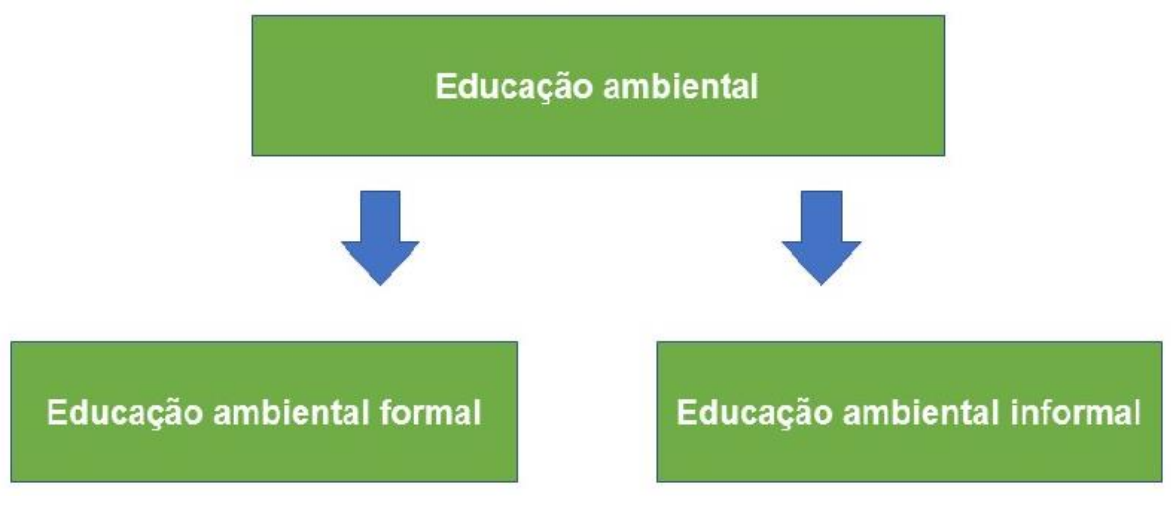

Figura 1. Modalidades da Educação Ambiental.

Fonte: Dias (2010).

A educação ambiental informal é aquela realizada "fora" dos muros escolares, ou seja, é aquela praticada de maneira informal junto à comunidade como um todo (coletividade). Envolve a flexibilidade de métodos e de conteúdos e um público-alvo muito variável em suas características: faixa etária, nível de escolaridade, nível de conhecimento da problemática ambiental, entre outros aspectos (COSTA, 2019).

Por outro lado, a educação ambiental formal é aquela praticada de acordo com os parâmetros escolares, ou seja, é um processo institucionalizado que ocorre nas unidades de ensino públicas e privadas, abrangendo todos os níveis de ensino (BARBOSA et al., 2015). A realização de ações práticas visando à valorização do espaço escolar como campo de formação de um sujeito ecológico capaz de atuar de forma crítica e pensante na sociedade na qual se insere mostrando as nuances conceituais envolvidas neste processo para a construção de uma prática efetiva (MELO et al., 2020).

Dias (2010), assim como outros autores, defende que a educação ambiental deve ser abordada como uma dimensão que permeia todas as atividades escolares perpassando os demais diversos setores de ação humana. 


\section{Educação ambiental no contexto escolar}

A inserção da educação ambiental nos currículos têm sido tema de debate e tem retomado à berlinda para se decidir se deve ou não ser uma disciplina ou se deve ser um tema transversal (MELO et al., 2020).

A educação ambiental deve ser abordada de forma sistemática e transversal em todos os níveis de ensino, assegurando a presença da dimensão ambiental de forma interdisciplinar nos currículos das diversas disciplinas e das atividades escolares (MARQUES et al., 2019).

Segundo Souza e Munhoz (2018), a natureza antidisciplinar provoca uma inserção por meio de projetos e/ou atividades extracurriculares. Nesse caso, é necessário analisar o cotidiano escolar para compreender como a educação ambiental vem se introduzindo nas práticas educativas e como outros contextos interferem e atuam sobre sua produção de sentidos e de racionalidades. Portanto, é preciso compreender a medição feita pelos alunos e professores sobre sentidos, representações e racionalidades geradas para além do conhecimento escolar.

De acordo com Almeida et al. (2020), a perspectiva de inserir questões ambientais no processo educativo requer que o professor oriente seu aluno a agir ativamente na sociedade $\mathrm{e}$ que o processo de aprendizagem não seja reduzido apenas ao aluno, mas possibilite ao professor o desenvolvimento constante de novas atitudes necessárias ao bom desempenho de sua profissão, compatíveis às frequentes mudanças socioambientais.

O pensar criticamente a ação pedagógica e seus efeitos devem proporcionar a fusão entre a prática e a teoria. Esta fusão é o alicerce da construção de uma pedagogia apropriada à educação ambiental, estando o professor munido de saberes pedagógicos (formação pedagógica) e estar preparado para acompanhar, entender e discutir as relações e o dinamismo que regem o ambiente (formação ambiental) (ALMEIDA et al., 2020).

Em 1981, foi instituída a Política Nacional de Meio Ambiente (PNMA) que determinava a orientação da educação em todos os níveis, desenvolvendo no cidadão e na comunidade a participação ativa no que diz respeito à defesa do meio ambiente, com a preocupação de que os currículos escolares trabalhem a questão ambiental nas disciplinas (BRASIL, 1981).

A interdisciplinaridade pretende garantir a construção de conhecimentos que rompam as fronteiras entre todas as disciplinas, também o envolvimento, compromisso, reciprocidade diante dos conhecimentos, ou seja, atitudes e condutas interdisciplinares. Portanto, a transversalidade e a interdisciplinaridade são, nesse sentido, modos de trabalhar o conhecimento que visam reintegração de dimensões isoladas uns dos outros pelo tratamento disciplinar. Com isso, pretende-se conseguir uma visão mais ampla da realidade que, tantas vezes, aparece fragmentada pelos meios de que dispomos para conhecê-la (ALMEIDA et al., 2020).

À educação ambiental cabe auxiliar os estudantes a adquirir conhecimentos, formar convicções que auxiliem na discussão desses conceitos e dos valores em que se fundamentam, uma vez que a política relativa ao meio ambiente depende do nível de consciência da responsabilidade social de cada pessoa. Assim, a educação ambiental passa a ter fundamental importância na formação do cidadão, sendo o sistema escolar formal a instituição que melhor oferece condições para implantá-la (SOUZA; MUNHOZ, 2018). 


\section{Desenvolvimento de projetos de educação ambiental}

De acordo com a Lei $n^{\circ}$. 9.795/99, a educação ambiental envolve a promoção de processos pedagógicos que favoreçam a construção de valores sociais, conhecimentos, habilidades e atitudes voltadas para a conquista da sustentabilidade socioambiental e a melhoria da qualidade de vida (BRASIL, 1999).

Entende-se que as escolas, por meio do processo de educação ambiental, constroem valores sociais, conhecimentos, habilidades, atitudes e competências voltadas para a conservação do meio ambiente, bem de uso comum do povo, essencial à sadia qualidade de vida e sua sustentabilidade (COSTA, 2015).

Devido a sua natureza pedagógica, vários projetos de educação ambiental foram desenvolvidos no âmbito escolar, dentre eles, podem ser citados: Barbosa et al. (2015), Medeiros et al. (2011), Costa (2015), Mattar et al. (2013), Cordula e Fonseca (2012), Costa (2013), Modesto e Araújo (2014), Passos et al. (2011), Pereira et al. (2014), Silva et al. (2015), Zampeze e Stroschoen (2014), Spada (2012), dentre outros.

Entretanto, tais projetos esbarraram em obstáculos quanto a sua elaboração e/ou execução seja por parte dos alunos, dos professores ou de outros fatores como, por exemplo, pela falta de um Projeto Político Pedagógico (PPP), atividades isoladas de educação ambiental, falta de recursos, falta de abordagem interdisciplinar, etc. como pode ser visto na tabela 1 .

Tabela 1. Pesquisadores no âmbito da educação ambiental formal e principais dificuldades encontradas na elaboração e execução dos projetos.

\begin{tabular}{ll}
$\begin{array}{c}\text { Pesquisadores em educação } \\
\text { ambiental formal }\end{array}$ & \multicolumn{1}{c}{$\begin{array}{c}\text { Dificuldades encontradas nos projetos de educação } \\
\text { ambiental }\end{array}$} \\
\hline Barbosa et al. (2015) & $\begin{array}{l}\text { Educação ambiental não é ministrada de forma } \\
\text { transversal e interdisciplinar; } \\
\text { Falta de recursos e incentivo. }\end{array}$ \\
\hline Cordula e Fonseca (2012) & $\begin{array}{l}\text { Desconexão fenomenológica dos docentes saberem } \\
\text { sobre educação ambiental e meio ambiente. }\end{array}$ \\
\hline Costa (2013) & Atividades isoladas de educação ambiental. \\
\hline Costa (2015) & $\begin{array}{l}\text { Percepção menos aguçada dos professores sobre os } \\
\text { impactos ambientais. }\end{array}$ \\
\hline Matar et al. (2013) & $\begin{array}{l}\text { Os alunos demonstraram dificuldade em ver a educação } \\
\text { ambiental como um processo de transformação. }\end{array}$ \\
\hline Medeiros et al. (2011) & Dificuldade dos professores em conscientizar os alunos. \\
\hline Modesto e Araújo (2014) & $\begin{array}{l}\text { Ausência de prática política pedagógica interdisciplinar } \\
\text { nas atividades de educação ambiental. }\end{array}$ \\
\hline Silva et al. (2015) & PPP não contempla a educação ambiental. \\
\hline Passos et al. (2011) & $\begin{array}{l}\text { Percepção equivocada dos alunos sobre a importância } \\
\text { dos insetos. }\end{array}$ \\
\hline Pereira et al. (2014) & Falta de estrutura e incentivo nas escolas. \\
\hline Spada (2012) & $\begin{array}{l}\text { Dificuldade dos professores de trabalhar a } \\
\text { interdisciplinaridade }\end{array}$ \\
\hline Zampeze e Stroschoen (2014) & $\begin{array}{l}\text { Dificuldade dos professores em desenvolver educação } \\
\text { ambiental de forma inter e transdisciplinar }\end{array}$ \\
\hline
\end{tabular}


É interessante salientar a importância em desenvolver esses projetos de forma interdisciplinar é devido à natureza complexa do meio ambiente, tendo, para isso, uma visão holística (DIAS, 2010).

Soma-se o fato de que a interdisciplinaridade é uma alternativa de integrar as diferentes dimensões dos fenômenos estudados, favorecendo um encontro entre disciplinas representadas por pessoas concretas, de modo que o êxito ou o fracasso de um projeto interdisciplinar depende, em grande medida, da empatia e capacidade para o trabalho grupal de tais pessoas: não se pode pensar em projetos interdisciplinares se não houver com equipes dispostas a construir coletivamente o conhecimento (SANTOS; BOER, 2020).

Diante desse prisma, o principal objetivo dos projetos de educação ambiental é auxiliar os estudantes a alcançar a ecoalfabetização, sendo que o foco da educação deve ser o desenvolvimento de habilidades que formem esse conceito. A ecoalfabetização para o cidadão é um processo de transformação, que envolve novos modos de ver o mundo e novos métodos de ação (BRASIL, 2012).

Diante dessa circunstância, é através desse processo de transformação que se dá o movimento de ação e conhecimento no que se refere à dinâmica de mudança. A educação ambiental tem a intencionalidade de romper com a alienação e proporcionar a construção de uma sociedade constituída de sujeitos mais preocupados com as questões ambientais no seu meio.

\section{Metodologia}

Os instrumentos utilizados para alcançar os objetivos da pesquisa foi de natureza qualitativa em artigos lidos e obtidos por meio da internet, tentando analisar os trabalhos de educação ambiental formal no que se refere a dificuldades de execução como, por exemplo: dificuldades de adesão dos demais professores, caráter interdisciplinar, continuidade das ações, entre outros.

As informações coletadas foram tabuladas em planilhas do Excel, sendo possível traçar o perfil de cada projeto de educação ambiental executado nas escolas.

\section{Resultados e Discussão}

Dificuldades na elaboração e execução dos projetos de educação ambiental nas escolas 
Diante dos vários projetos de educação ambiental a serem executados nas escolas, deve-se deixar claro a intenção de fazê-los de forma participativa, envolvendo o corpo docente em toda a etapa do processo. Para isso, é necessário marcar uma reunião com todos os professores e direção para a elaboração do projeto, abrindo espaço para o diálogo e para a contribuição de cada um de acordo com sua área do conhecimento.

$E^{E}$ nesse contexto que se insere as metodologias da pesquisa-ação/pesquisaparticipativa, pois buscam articular a produção de conhecimento, ação educativa e participação dos envolvidos para a compreensão e intervenção junto à realidade local por meio de ações de educação ambiental.

Para Carneiro e Santos (2020), a pesquisa-ação tem como ponto de partida a articulação entre a produção de conhecimentos para a conscientização dos sujeitos e solução de problemas socialmente significativos.

Entretanto, pelas experiências vivenciadas, na maioria das vezes, por mais que os professores sinalizem uma colaboração na elaboração e execução do projeto ambiental, discutindo as temáticas na sala de aula de acordo com o enfoque da sua disciplina por meio das ferramentas disponíveis para tal (cartazes, textos, músicas, tabelas, gráficos, discussões, dentre outras), na realidade não é isso que ocorre.

Diante dessa situação, a elaboração e/ou execução dos projetos de educação ambiental no âmbito formal encontra alguns entraves para o seu desenvolvimento, dentre eles podem ser citados:

- Falta ou não cumprimento de planejamento;

- Relacionamentos interpessoais conflituosos;

- Falta de entendimento do objetivo do projeto;

- Percepções equivocadas sobre as temáticas ambientais;

- Falta de compromisso de alguns professores e/ou alunos;

- Maior participação nas atividades práticas;

- Convicções exageradas (pessimismo/otimismo exagerado);

- Não abertura a mudança de hábitos, comportamentos e atitudes;

- Falta de interesse para as ações práticas e/ou teóricas;

- Falta de recursos para as atividades propostas

Além disso, a falta de interesse dos professores tem fatores bem complexos como, por exemplo, a falta de valorização do profissional, desvalorização salarial, sobrecarga de trabalho, falta de incentivo de participação em projetos, dentre outros.

$\mathrm{Na}$ realidade, nota-se que um projeto de educação ambiental é difícil de ser desenvolvido, uma vez que, além dos fatores supracitados, é necessário que haja professores capacitados e interessados a entender todas as dimensões das questões ambientais.

Nessa mesma perspectiva, Santos et al. (2020) destaca alguns fatores que se tornam um empecilho ao dos professores nos projetos de educação ambiental, dentre eles: o tamanho da escola, o número de alunos e de professores, a predisposição destes professores em passar por um processo de treinamento, a vontade da diretoria de implementar um projeto ambiental que vá alterar a rotina na escola, etc.

Durante a Conferência de Tbilisi (1970), a cogitação desses fatores já foram pontos de preocupação entre os eventos, resultando na recomendação $n^{\circ} .21$ a qual alega que deveriam 
ser efetuadas pesquisas sobre os obstáculos, inerentes ao comportamento ambiental, que se opõem às modificações dos conceitos, valores e atitudes das pessoas (DIAS, 2010).

Tal fato é lamentável, uma vez que o professor tem grande importância na formação de opinião do indivíduo, pois ele estimula a busca pelo conhecimento e, por meio da promoção da discussão, permite a formação de cidadãos críticos com a realidade econômica, social, política e ambiental.

Soma-se a isso, o fato de não haver um entendimento sobre noções básicas de educação ambiental voltados aos profissionais da educação, gerando uma confusão sobre termos, procedimentos, práticas e abordagens sobre as temáticas ambientais. Desse modo, os projetos ficam fadados ao insucesso, não atingindo seus objetivos de sensibilização e de mudanças de hábitos, comportamentos e atitudes do cidadão, não o despertando para uma relação mais harmônica com o meio natural.

Situação como essa já fora detectado por Santos e Bento (2012), Costa et al. (2012), Barbosa et al. (2015), Peixoto et al. (2013), Costa (2015), dentre outros, ao desenvolverem projetos de educação ambiental no âmbito escolar.

Tal fato, equivoca os professores, uma vez que os mesmos não sabem se seus projetos são de caráter inter ou transdisciplinar, multi ou pluridisciplinar, sendo que há uma abordagem diferenciada para cada termo com relação a objetivos, metodologia e resultados esperados.

A falta de capacitação dos professores ou da comunidade escolar gera uma confusão no uso desses termos quando há a elaboração e/ou desenvolvimento de algum projeto de educação ambiental com os alunos. Por isso, é interessante ter em mente o conceito de cada um, permitindo que os objetivos elencados, a metodologia adotada e os resultados esperados sejam atingidos.

Os termos multidisciplinaridade, pluridisciplinaridade, interdisciplinaridade e transdisciplinaridade são conceituados, primeiramente, por Jantsch (1972), Santomé (1998) e Zakrzevski e Coan (2003) como:

Multidisciplinaridade: não há uma integração ou relação entre as disciplinas;

Pluridisciplinaridade: há uma relação primária entre disciplinas, gerando troca de informações, uma acumulação de conhecimentos, porém é algo extremamente superficial;

Interdisciplinaridade: é a cooperação entre as disciplinas, favorecendo a intercâmbios e enriquecimentos recíprocos. Isso favorece a uma dependência entre as disciplinas para a construção ou enriquecimento do conhecimento;

Transdisciplinaridade: uma construção de um sistema total de integração, sem fronteiras sólidas entre as disciplinas. É alcançada através de sucessivas atividades interdisciplinares, que possam ser expandidas às sociedades.

Inúmeros são os projetos ambientais que no início sugere uma abordagem interdisciplinar; na prática acaba sendo desenvolvido em base multidisciplinar, pois são poucos os professores que tem interesse em participar e pela falta de conhecimento acabam trabalhando as temáticas ambientais de forma isolada nas suas disciplinas. 
Corroborando com tal premissa, Santos e Boer (2020) sugerem que a prática dos projetos em educação ambiental é incipiente de interdisciplinaridade, centrada em perspectivas comportamentalistas e individualistas, meramente conteudista restrita a cada disciplina e informativa na transmissão de conhecimentos.

O ideal seria que os projetos ambientais tivessem um viés interdisciplinar, uma vez que não haveria uma barreira entre as disciplinas no que se refere à discussão dos temas ambientais. Tal premissa é defendida por Brasil (2012) ao afirmar que a interdisciplinaridade visa a garantir a construção de um conhecimento globalizante, rompendo com as fronteiras das disciplinas.

$\mathrm{Na}$ prática, pelas observações feitas durante os projetos de educação ambiental realizados nas escolas públicas na cidade de Aracaju e interior do estado de Sergipe, os professores despertaram o interesse em saber o dia e horário das atividades pelo fato de que naquele momento eles não precisavam dar aula. Dessa forma, o corpo docente, diante da sua grande importância pedagógica, reduziu-se a simples figura de observador do trabalho que estava sendo desenvolvido com os alunos, mesmo sendo convidados a participar do projeto, pautando-se dos princípios da pesquisa-ação e pesquisa-participante.

Diante de tantos obstáculos, a melhor forma de trabalhar a educação ambiental nas escolas, de acordo com Melo et al. (2020) é inserindo as temáticas ambientais nos currículos escolares, como atividades artísticas, experiências práticas, atividades fora de sala de aula, produção de materiais locais, projetos ou qualquer outra atividade que conduza os alunos a serem reconhecidos como agentes ativos no processo que norteia a política ambientalista. Assim, cabem aos professores, por intermédio de prática interdisciplinar, proporem novas metodologias que favoreçam a implementação da Educação Ambiental, sempre considerando o ambiente imediato, relacionado a exemplos de problemas atualizados.

As experiências práticas e atividades fora da sala de aula tem como contribuição as Expedições Científicas Estudantis como recurso metodológico, onde os alunos se organizam em torno de temas ou problemas ambientais específicos da região e saem a campo devidamente instrumentalizados e motivados a observar, analisar e coletar dados, desenvolvendo atitudes e habilidades científicas (FONSECA; SHUVARTZ, 2019).

Esse tipo de estudo, onde o aluno constrói o conhecimento junto com o professor, gera um maior aproveitamento, pois quando o aluno é instigado para investigar as prováveis causas para um determinado problema e suas possíveis consequências para o ambiente analisado, ele se sente importante por estar agindo junto com o professor e acabam se interessando ainda mais pelo assunto.

A partir dessa metodologia, os fragmentos de disciplinas utilizados pela maioria das escolas, são interligados com a finalidade de facilitar a aprendizagem dos alunos, que perceberão que História, Biologia, Geografia e outras disciplinas têm muitas coisas em comum. Desta forma, eles irão associar um fato histórico para entender um fenômeno físico, por exemplo.

Outro ponto que cabe ser destacado é que o Projeto Político Pedagógico (PPP) não inclui atividades de educação ambiental na maioria das escolas que foram desenvolvidos os projetos de educação ambiental, sendo um empecilho para que a educação ambiental seja trabalhada em todas as disciplinas. Dessa maneira, de forma prática, não há uma relação das temáticas ambiental com os conteúdos curriculares. 
Tal fato, também, foi observado por Domingues (2013) em um estudo sobre a educação ambiental no ensino fundamental no Colégio de Aplicação (CODAP) na Universidade Federal de Sergipe, pois a inclusão de ações de educação ambiental ao Projeto Político Pedagógico impedia estreitar a relação meio ambiente e currículo disciplinar.

A falta de uma estrutura pedagógica que trate a educação ambiental como prática transversal e interdisciplinar se torna um obstáculo no que se refere a uma abordagem relacionística da educação ambiental com as disciplinas escolares. Dessa maneira, há um predomínio de atividades pontuais e sem resultados expressivos não atingindo aos objetivos apregoados pela Política Nacional de Educação Ambiental de um processo dinâmico, participativo e permanente, por exemplo.

A importância da elaboração e execução dos projetos de educação ambiental está pautada, segundo Souza e Marco (2020), à tomada de consciência e de reflexões críticas necessárias a uma ação transformadora e emancipatória, pois tem a finalidade de sensibilizar e transformar a comunidade envolvida em pessoas capazes de mudar suas posturas individuais, pois, os envolvidos deverão se tornar multiplicadores de ideias.

Por outro lado, em vários projetos de educação ambiental sendo executados pelas escolas com ações isoladas e restritas a datas comemorativas como o Dia da Árvore, Dia do Meio Ambiente, Dia da Água, Dia Internacional da Biodiversidade, Dia do Índio, Dia do Solo e outras as quais são tachadas como sendo atividades de educação ambiental.

No entanto, tais atividades não surtem o efeito desejado. Para a UNESCO e vários autores especialistas na área, há um consenso de que educação ambiental é um processo permanente e contínuo visando a mudança de hábitos, comportamentos e atitudes dos indivíduos. Então, ações isoladas em datas ambientais não se encaixam nos aspectos conceituais da educação ambiental, necessitando de uma formação complementar de todos os atores sociais envolvidos não somente no âmbito escolar, mas além muros da escola, devido à complexidade dos fatores que constituem a educação ambiental.

Vale a pena ressaltar que um dos objetivos do ProNEA (Programa Nacional de Educação Ambiental) é estimular e apoiar processos de formação ambiental continuada e inicial de professores dos sistemas de ensino, como também a formação de educadores ambientais, buscando a transversalidade construída a partir de uma perspectiva inter e transdisciplinar. Dessa forma, a educação para a conservação da natureza visa mudar a atitude das pessoas, resultando em comportamentos de conservação e não de degradação (COSTA, 2019).

Os projetos de educação ambiental são importantes práticas pedagógicas com objetivo de despertar a necessidade de mudança de paradigmas e de encarar o papel do ser humano na natureza no que se refere a adoção de medidas mais sustentáveis no cotidiano.

\section{Considerações finais}

Diante da diversidade e complexidade dos fatores negativos que interferem na elaboração e execução dos projetos de educação ambiental, é necessário que os professores tenham uma visão holística sobre as temáticas. Para isso, os projetos educação ambiental devem ser executados de forma interdisciplinar para que se possa alcançar os objetivos e 
Revista da Universidade Estadual de Alagoas/UNEAL e-ISSN 2318-454X, Ano 12, Vol. 12(2), 2020

princípios da educação ambiental, porém algumas dificuldades são da própria organização das instituições de ensino, onde há a fragmentação dos saberes em disciplinas, o que torna difícil a tomada da consciência destas relações observadas no mundo.

Além disso, muitas ações dos projetos de educação estão restritas a comemorações de datas ambientais, sendo ações isoladas e pontuais, indo de encontro aos princípios de dinâmico e permanente que o processo deve possuir. Tais projetos de educação ambiental não atingem os objetivos esperados e não motivam a participação de todos os envolvidos no espaço escolar.

Tais projetos de educação ambiental exigem uma nova configuração no meio escolar com objetivos e metodologias interdisciplinares e sua inclusão nos Projetos Político Pedagógicos, envolvendo a qualificação do professor e inclusão do saber ambiental a nova proposta político-pedagógica.

\section{Conflito de interesses}

Os autores deste manuscrito não declararam conflitos de interesse. 


\section{Referências}

ALMEIDA, B. C.; PORTO, L. J. L. S.; SILVA, C. M. Construção de histórias em quadrinhos como recurso didático para a educação ambiental. Revista Brasileira de Educação Ambiental, v. 15, n. 3, p. 229-245, 2020.

BARBOSA, E. S.; SILVA, A. C.; PEREIRA, K. C.; ARAÚJO JÚNIOR, A. C. R. Princípios e práticas de educação ambiental na Escola Presidente Costa e Silva em Boa Vista/RR. Revista educação ambiental, n. 53, p. 1-16, 2015.

BARROS, D. R.; SILVA, M. N. A conscientização do homem para uma exploração sustentável do meio ambiente. Revista educação, psicologia e interfaces, v. 3, n. 2, p. 121135, 2019.

BRASIL. LEI No . 6.938, de 31 de agosto de 1981. Dispõe sobre a Política Nacional de Meio Ambiente, seus fins e mecanismos de formulação e aplicação e dá outras providências.

Disponível em: http://www.planalto.gov.br/ccivil_03/LEIS/L6938.htm. Acesso em: 13 de Jul. 2020.

BRASIL. LEI No $\mathbf{N}^{\mathbf{.} 9.795}$, de 27 de abril de 1999. Dispõe sobre a educação ambiental, institui a Política Nacional de Educação Ambiental e dá outras providências. Disponível em: www.planalto.gov.br. Acesso em: 15 de Nov. 2012.

BRASIL - Secretaria de Educação Continuada, Alfabetização, Diversidade e Inclusão. Vamos cuidar do Brasil com escolas sustentáveis: educando-nos para pensar e agir em tempos de mudanças socioambientais globais. Ministério da Educação, Secretaria de Educação Continuada, Alfabetização, Diversidade e Inclusão, Ministério do Meio Ambiente; elaboração de texto: Tereza Moreira - Brasília: A Secretaria, 2012.

CARNEIRO, D. O.; SANTOS, M. A. F. Interfaces da educação ambiental: um estudo em uma Associação Comunitária do Semiárido baiano. Revista educação ambiental, v. 1, n. 1, p. 1120, 2020.

CÓRDULA, E. B. L.; FONSECA, P. N. Análise da Interpretação sobre Educação Ambiental dos Profissionais Atuantes em uma Escola Pública Municipal de Cabedelo-PB. Educação Ambiental em Ação. v. 39, p. 1-12, 2012.

COSTA, C. C. Percepção ambiental em escola rural de Sergipe. Educação Ambiental em Ação, v. 46, p. 01, 2013.

COSTA, J. R.; SOARES, J. E. C.; TÁPIA-CORAL, S.; MOTA, A. M. A percepção ambiental do corpo docente de uma escola pública rural em Manaus (Amazonas). Revista Brasileira de Educação Ambiental. v. 7, p. 63-67, 2012.

COSTA, C. C. Percepção ambiental dos acadêmicos de Engenharia Florestal pela Universidade Federal de Sergipe. Revista Educação Ambiental em Ação. v. 13, n. 51, p. 1$18,2015$.

COSTA, C. C. Percepção ambiental: como o meio ambiente é percebido. Alemanha: Novas edições acadêmicas, 2019.

DIASS, G. F. Educação ambiental: princípios e práticas. 9ª ed. São Paulo: Gaia, 2010.

DOMINGUES, E. T. F. A educação ambiental no ensino fundamental do Colégio de

Aplicação (CODAP): concepções e práticas. Revista Histedbr, v. 12, n. 8, p. 336-356, 2013. 
FONSECA, D. M.; SHUVARTZ, M. A contribuição dos livros didáticos de Ciências da educação de jovens e adultos para o ensino da educação ambiental. In: XII Encontro Nacional de Pesquisa em Educação em Ciências, 2019.

JANTSCH, E. Toward interdisciplinarity and transdisciplinarity in education and innovation (97-121). In: CERI \& OECD (Eds.) Interdisciplinarity. Paris: CERI \& OECD, 1972. JESUS, I. T. A dimensão socioambiental na perspectiva de educadores ambientais do município de Lagarto-SE. Revista Sergipana de Educação Ambiental, v. 1, n. 2, p. 78-93, 2015.

MARQUES, J. L.; CORREIA, J. A.; DURÉ, R. C.; LUCENA, L. D. S.; ABÍLIO, F. J. P. Educação ambiental escolar: percepções ambientais dos alunos de uma escola no Semiárido paraibano. In: VI Congresso Internacional das Licenciaturas, 2019.

MATTAR, S. V. A.; MAY, D.; MARANHO, L. T. Elaboração de um programa de Educação Ambiental em escola particular no município de Curitiba, Paraná. Educação Ambiental em Ação, n. 45, setembro/novembro 2013.

MEDEIROS, A. B.; MENDONÇA, M. J. S. L.; SOUSA, G. L.; OLIVEIRA, I. P. A Importância da educação ambiental na escola nas séries iniciais. Revista Faculdade Montes Belos, v. 4, n. 1, P. 1-17, 2011.

MELO, J. R.; CINTRA, L. S.; LUZ, C. N. M. Educação ambiental: reciclagem do lixo no contexto escolar. Revista multidebates, v. 4, n. 2, p. 133-141, 2020.

MINISTÉRIO DO MEIO AMBIENTE. Documento Online. Sustainable Production \& Consumption: Making the Conection. Sessão II. Contexto global de consumo e produção sustentáveis. Padrões de consumo atuais. 2016. Disponível em:

http://www.mma.gov.br/estruturas/a3p/_arquivos/consumo_producao_sustentavel.pdf. Acesso em: 12 Jul. 2020.

MODESTO, M. A.; ARAÚJO, M. I. O. É brincando que se aprende ou se forma? Uma experiência de educação ambiental em uma escola pública sergipana. Revista Sergipana de Educação Ambiental. v. 1, nº 1, p. 101-117, 2014.

PASSOS, E. M. dos; RIBEIRO, G. T.; PODEROSO, J. C. M.; COSTA, C. C.; GOMES, L. J. Os insetos concepção dos alunos e professores de ciências de diferentes realidades no município de Itabaiana-SE. Educação Ambiental em Ação, v. 36, p. 1-12, 2011.

PEIXOTO, M. F. C. C.; LIMA, J. R.; SANTOS, A. M. S.; CALEGARI, L. Percepção no ambiente acadêmico sobre sustentabilidade ambiental e o uso do papel. Caminhos de Geografia, v. 14, n. 47, p. 74-84, 2013.

PEREIRA, C. G.; SILVA, L. F.; SOUZA, L. O.; SOUZA, R. F. Um estudo diagnóstico sobre educação ambiental nas escolas do ensino fundamental e médio de São Miguel do GuamáPará. Enciclopédia Biosfera. v.10, n.19 p. 1-15, 2014.

RUSCHEINSKY. A. Educação ambiental: abordagens múltiplas. Porto Alegre: Artmed, 2002.

SANTOMÉ, J. T. Globalização e Interdisciplinaridade - o currículo integrado. Porto Alegre: Artes Médicas, 1998.

SANTOS, A. A. M.; BENTO, J. S. A Percepção Ambiental dos Professores e Alunos da Educação de Jovens e Adultos. Revista de Ciência, Tecnologia e Humanidades do IFPE, v. 4, n. 1, p. 38-45, 2012.

SANTOS, C. B.; BOER, N. A poesia de Cora Coralina e o teatro-educação: uma alternativa interdisciplinar para trabalhar a educação ambiental. Revista Ibero-Americana de humanidades, ciências e educação, v. 6, n. 2, p. 20-28, 2020.

SANTOS, K. F.; CARVALHO, E. T.; HERRERA, M. R. G. A interpretação ambiental na perspectiva dos projetos do Departamento de Extensão do Instituto Federal do mato Grosso, campus Cárceres. Research, society and development, v. 9, n. 6, p. 1-18, 2020. 
SILVA, G. N., SANTOS, C. K. S.; SANTOS, M. J. B. A.; SANTOS, T. A. A educação ambiental formal como ferramenta de sensibilização para a coleta seletiva na EMEF Olga Benário, em Aracaju/SE. Revista Sergipana de Educação Ambiental, v. 1, n. 2, p. 55-77, 2015

SOUZA, P. C.; MARCO, R. Educação crítica. Educação reflexiva, o ensino aprendizagem da saúde e meio ambiente: uma contribuição do enfoque interdisciplinar. Revista unisa, v. 1, p. 61-79, 2020.

SOUZA, D. C.; MUNHOZ, R. H. A inserção da educação ambiental no currículo escolar: um estudo de caso da política curricular do Estado de São Paulo. Revista Eletrônica de Humanidades do Curso de Ciências Sociais da UNIFAP, v.11, n.22, p. 51-32, 2018. SPADA, I. P. Desafios da Educação Ambiental no Ensino Formal. Revista Educação Ambiental em Ação. n. 41, p. 1-12, 2012.

ZAMPEZE, M.; STROSCHOEN, A. A. G.; Educação ambiental nas escolas de educação básica do município de Guaporé/RS. Revista Educação Ambiental em Ação, n. 47, 2014. ZAKRZEVSKI, S. B.; COAN, C. M. Interdisciplinaridade e educação ambiental. In: A Educação ambiental na escola: abordagens conceituais/organizado por Sônia Balvedi Zakrzevski. Erechim/RS: Edifapes, 2003. 